\title{
DESCRIÇÃO DO QUADRO PRONOMINAL PRESENTE TANTO NOS PRINCIPAIS COMPÊNDIOS GRAMATICAIS TRADICIONAIS QUANTO NAS GRAMÁTICAS DE ORIENTAÇÃO LINGUÍSTICA
}

\author{
DESCRIPCIÓN DEL MARCO PRONOMINAL PRESENTE ENTRE LAS PRINCIPALES \\ COMPENDIOS GRAMATICALES TRADICIONALES Y EN LA GRAMÁTICA DE \\ ORIENTACIÓN LINGÜÍSTICA
}

\begin{abstract}
DESCRIPTION OF PRONOMINAL FROM THE BOARD PRESENT BOTH IN THE MAIN TRADITIONAL GRAMMARS HOW MUCH LINGUISTICS ORIENTATION GRAMMARS
\end{abstract}

Cátia Cilene Pereira Meireles CUNHA ${ }^{1}$ Maricineia Pereira Meireles da SILVA ${ }^{2}$

RESUMO: Dentre os fenômenos variáveis presentes no Português Brasileiro, há um que é instigante, pois, apesar de presente na oralidade da norma culta urbana, ainda não goza de franca aceitação na modalidade escrita, sobretudo a praticada no âmbito escolar: a variação nós/a gente para a expressão da primeira pessoa do plural(P4). O presente artigo apresentará a descrição do quadro pronominal do português nas gramáticas normativas e nas de orientação linguística. Também serão apresentados resultados de pesquisas sociolinguísticas sobre o uso de <a gente>. Verificou-se que as gramáticas normativas não descrevem no quadro pronominal do Português Brasileiro o fenômeno variável para expressão do $\mathrm{P} 4$, desprestigiando o falar usual dos brasileiros. Já as gramáticas descritivas, de modo geral, conferem ao pronome inovador um status desprestigioso e informal, restringindo-o à oralidade. Tais gramáticas ignoram as pesquisas sociolinguísticas que confirmam a presença de <a gente> mesmo no falar culto urbano em meios acadêmicos e padronizadores.

PALAVRAS-CHAVE: Quadro pronominal. Gramática normativa/descritiva. Fenômeno variável.

RESUMEN: Entre los fenómenos variables presentes en el portugués brasileño, hay uno que es intrigante, porque, a pesar de presente en la oralidad de la norma culta urbana, todavía no goza de una aceptación franca en la modalidad escrita, especialmente la practicada en el contexto escolar: La variación we / a gente para la expresión de la primera persona plural (P4). Este artículo presentará la descripción del marco pronominal portugués en gramáticas normativas y lingüísticas. También se presentarán los resultados de la investigación sociolingüística sobre el uso de <a gente>. Se encontró que las gramáticas normativas no

1 Universidade Federal Rural do Rio de Janeiro (UFRRJ), Seropédica - RJ - Brasil. Mestra em Letras. Professora na Rede Estadual do Rio de janeiro. ORCID: https://orcid.org/0000-0001-6081-0660. E-mail: catiameireles@yahoo.com.br

2 Centro Universitário de Volta Redonda (UniFOA), Volta Redonda - RJ - Brasil. Mestrado acadêmico Interdisciplinar em Saúde e Educação. Mestrado em Gestão e Estratégia em Negócios (UFRRJ). Especialização em Língua Portuguesa. Professora no Centro Universitário de Barra Mansa (UBM). ORCID: https://orcid.org/0000-0003-4413-6551. E-mail: maricineia@uol.com.br

Doxa: Rev. Bras. Psico. e Educ., Araraquara, v. 21, n. 1, p. 104-127, jan./jun. 2019. 
describen en el marco pronominal del portugués brasileño el fenómeno variable para la expresión de P4, desacreditando el habla habitual de los brasileños. Las gramáticas descriptivas, por otro lado, le dan al pronombre innovador un estatus de desprecio y no formal, restringiéndolo a la oralidad. Tales gramáticas ignoran la investigación sociolingüística que confirma la presencia de "incluso personas" en el culto urbano que habla en entornos académicos y de estandarización.

PALABRAS CLAVE: Marco pronominal. Gramática normativa / descriptiva. Fenómeno variable.

ABSTRACT: Among the variable phenomena present in Brazilian Portuguese, there is one that is intriguing, because, although present in the orality urban of the educated norm, it still does not enjoy frank acceptance in the written modality, especially the one practiced in the school context: the variation we / a gente for the expression of the first person plural (P4). This article will present the description of the Portuguese pronominal framework in normative grammars and linguistic ones. Results of sociolinguistic research on the use of $<$ people> will also be presented. It was found that normative grammars do not describe in the pronominal framework of Brazilian Portuguese the variable phenomenon for P4 expression, discrediting the usual speech of Brazilians. Descriptive grammars, on the other hand, give the innovative pronoun a discretious and informal status, restricting it to orality. Such grammars ignore sociolinguistic research that confirms the presence of "a gente" in urban cult talking in academic and standardizing environments.

KEYWORDS: Pronominal framework. Normative / descriptive grammars. Variable phenomenon.

\section{Introdução}

A língua não é uniforme, homogênea, mas repleta de variedades dotadas de organização estrutural própria, ou seja, suas respectivas normas. Segundo Faraco (2008), norma, nesse sentido, representa o que é corriqueiro, usual e normal para determinado grupo de falantes. Em outras palavras, os fenômenos linguísticos manifestados nos diferentes componentes gramaticais (fonética, fonologia, morfologia, sintaxe) e também no léxico de uma comunidade de fala constituem a sua norma, que não comporta apenas fenômenos fixos, mas também fenômenos em variação.

Dentre os fenômenos variáveis presentes no Português Brasileiro (PB), há um que é instigante, pois, apesar de muito presente na oralidade da norma culta urbana, ainda não goza de franca aceitação na modalidade escrita, sobretudo a praticada no âmbito escolar: a variação nós/ a gente para a expressão da primeira pessoa do plural ou $\mathrm{P} 4^{3}$.

${ }^{3}$ Há autores, como Lopes (2003, 2007), que preferem o termo P4 (quarta pessoa) à tradicional nomenclatura "primeira pessoa do plural", sob o argumento de que tal pessoa gramatical não seria propriamente o plural de $e u$ 
Na modalidade oral do PB, o tradicional pronome <nós> frequentemente é substituído pela forma <a gente>, produto de um processo de gramaticalização do nome gente para exprimir a primeira pessoa do plural, de acordo com a afirmação de Omena (2003). A preferência do falante pela forma inovadora, segundo Lopes (1996), se dá pelo fato de ela proporcionar um descompromisso do indivíduo com o discurso, tornando este mais vago e genérico, pois tal variante pode englobar as demais pessoas.

$\mathrm{O}$ crescente uso da forma <a gente> no PB foi confirmado por diversas pesquisas realizadas no âmbito da Sociolinguística.

Não obstante a entrada de <a gente> concorrendo com <nós> no PB, percebe-se que há uma orientação na praxe escolar no que diz respeito ao emprego da variante tradicional na modalidade escrita, haja vista a correção a que está sujeita a forma inovadora, caso apareça em textos escritos, pelo fato de ser tratada como marca de oralidade. É necessário, pois, contextualizar o fenômeno variável no âmbito do ensino, a fim de que a variante inovadora não seja simplesmente tachada como "erro" nos registros escritos, mas uma possibilidade a ser usada a depender do contexto linguístico. Diante disso a presente pesquisa tratou da variação na expressão da primeira pessoa do plural em gêneros textuais escritos de alunos do $9^{\circ}$ ano do Ensino Fundamental.

Por conseguinte, o presente artigo tem como objetivo geral apresentar a descrição do quadro pronominal do português, observando o tratamento dado pelas gramáticas normativas de língua portuguesa ao assunto em contraste com o que aparece nas gramáticas de orientação linguística e concluindo com um levantamento dos resultados de pesquisas sociolinguísticas sobre a variação na expressão de $\mathrm{P} 4$.

Como objetivos específicos, pretendemos o seguinte: legar uma contribuição ao ensino de língua portuguesa no que diz respeito ao conhecimento a respeito da abordagem da variação linguística em sala de aula a partir de um trabalho sistemático com um fenômeno variável, qual seja, a alternância nós/ a gente.

Com o objetivo de investigar a prescrição dada pelas gramáticas tradicionais ao quadro pronominal, demonstrando a abordagem de $\mathrm{P} 4$, verificaremos três gramáticas de autores consagrados, quais sejam, a Gramática Normativa da Língua Portuguesa, de Rocha Lima (2008 [1972]); a Moderna Gramática Portuguesa, de Evanildo Bechara (2007); a Nova Gramática do Português Contemporâneo, de Celso Cunha e Lindley Cintra (2007 [1985]).

$($ eu + eu), mas sim a expressão de outra realidade (eu + alguém). No entanto, como a praxe escolar faz largo uso da nomenclatura tradicional, neste trabalho tomaremos, por razões práticas, os dois termos como equivalentes. 
As gramáticas científicas (descritivas) ou de orientação linguística buscam pesquisar e analisar um conjunto de características próprias de determinada variedade de uma língua. Segundo Travaglia (2001), nessas gramáticas há uma descrição da estrutura e do funcionamento de determinada variedade linguística, de sua forma usual em uma comunidade de fala. Verificaremos, portanto, o quadro pronominal apresentado nas seguintes gramáticas descritivas que se ocuparam da variedade culta do PB: Gramática de usos do português, de Neves (2011); Gramática Houaiss da língua portuguesa, de Azeredo (2008); Nova Gramática do Português Brasileiro, de Castilho (2010); Gramática Pedagógica do Português Brasileiro, de Bagno (2011).

Da mesma forma, foram analisadas algumas pesquisas sociolinguísticas que se ocuparam do uso da forma <a gente> em concorrência com <nós> na variedade brasileira do português. Assim, faremos um levantamento de trabalhos representativos sobre o fenômeno da variação na expressão de P4 em diferentes regiões brasileiras. tais como os estudos feitos por Omena (1996, 2003), Lopes (1996, 2003, 2007), Machado (1995), Maia (2003), Rocha (2009), Mendonça (2010) e Vianna (2011).

Almejamos que o presente trabalho contribua para que muitos docentes superem duas dicotomias ainda muito presentes no ensino de Língua Portuguesa: por um lado, a do certo/errado herdada da tradição escolar; por outro, a do formal/informal estabelecida como alternativa à primeira, mas com o inconveniente de confundir variação com informalidade.

Em última análise, esperamos que os professores possam desenvolver um ensino de Língua Portuguesa sob a perspectiva da variação linguística. Além disso, pretendemos com esta pesquisa promover a autonomia do discente para que faça escolhas de estruturas linguísticas que denotem a adequação requerida em cada variedade da língua portuguesa, ou seja, em cada norma de uso.

\section{Revisão bibliográfica}

Faremos um levantamento da descrição do quadro pronominal presente tanto nos principais compêndios gramaticais tradicionais quanto nas gramáticas de orientação linguística. Além disso, serão abordados alguns trabalhos acadêmicos representativos sobre o fenômeno da variação nós/ a gente no PB. 


\section{A Abordagem das Gramáticas Tradicionais de Língua Portuguesa}

$\mathrm{Na}$ abordagem feita pelas gramáticas tradicionais, privilegia-se a prescrição de regras a partir de usos de escritores clássicos da Literatura, o que gera um distanciamento em relação à língua que efetivamente é falada. Assim, a descrição das gramáticas tradicionais não considera a heterogeneidade da língua, a interação entre os falantes nem as variações existentes, que passam a ser consideradas como desvios da norma gramatical.

Tradicionalmente, assume-se que os pronomes pessoais do caso reto servem para desempenhar a função de sujeito das orações, e os oblíquos, geralmente para a função de complemento dos verbos. Com o objetivo de investigar a prescrição dada pelas gramáticas tradicionais ao quadro pronominal, demonstrando a abordagem de $\mathrm{P} 4$, verificaremos três gramáticas de autores consagrados, quais sejam, a Gramática Normativa da Língua Portuguesa, de Rocha Lima (2008 [1972]); a Moderna Gramática Portuguesa, de Evanildo Bechara (2007); a Nova Gramática do Português Contemporâneo, de Celso Cunha e Lindley Cintra (2007 [1985]).

Rocha Lima (2008) não elenca em sua gramática o termo <a gente> como uma das formas de expressão da primeira pessoa do plural, embora reconheça o <você> como segunda pessoa (P2) ao lado de <tu> na listagem de pronomes pessoais das formas retas (p. 316). Nem mesmo em notas de rodapé o autor faz alusão à variação na expressão de $\mathrm{P} 4$ no PB, sendo esta a distribuição das formas retas dos pronomes pessoais segundo ele:

Quadro 1 - Distribuição dos pronomes retos segundo Rocha Lima

\begin{tabular}{|c|c|c|}
\hline $1^{\mathrm{a}}$ pessoa & $2^{\mathrm{a}}$ pessoa & $3^{\mathrm{a}}$ pessoa \\
\hline eu & tu, você & ele, ela \\
\hline nós & vós, vocês & eles, elas \\
\hline
\end{tabular}

Fonte: Adaptado de Rocha Lima (2008, p. 316)

Do mesmo modo, Bechara (2007), em sua gramática, exclui do quadro pronominal a forma <a gente>, conforme podemos constatar no quadro de pronomes descrito por ele:

Quadro 2 - Distribuição dos pronomes retos segundo Bechara

Pronomes Pessoais Retos

$1^{\mathrm{a}}$ pessoa $\mathrm{eu}$ 


\begin{tabular}{|c|c|c|}
\hline \multirow{2}{*}{ Singular } & $2^{\mathrm{a}}$ pessoa & tu \\
\cline { 2 - 3 } & $3^{\mathrm{a}}$ pessoa & ele, ela \\
\hline \multirow{4}{*}{ Plural } & $1^{\mathrm{a}}$ pessoa & nós \\
\cline { 2 - 3 } & $2^{\mathrm{a}}$ pessoa & vós \\
\cline { 2 - 3 } & $3^{\mathrm{a}}$ pessoa & eles, elas \\
\hline
\end{tabular}

Fonte: Adaptado de Bechara (2007, p. 164)

No entanto, sem poder ignorar o expressivo uso oral da forma <a gente> na variedade brasileira do português, ele põe uma observação em fonte diminuta para mencionar a variação que ora estudamos. Segundo o autor, "o uso do substantivo gente precedido de artigo $a$ e em referência a um grupo de pessoas que se inclui na fala, ou a esta sozinha, passa a pronome e se emprega fora da linguagem cerimoniosa" (BECHARA, 2007, p. 166). O gramático também destaca nessa observação que em ambos os casos o verbo deverá ficar na $3^{\text {a }}$ pessoa do singular e, para exemplificar o adendo, apresenta o seguinte excerto:

(03) É verdade que a gente, às vezes, tem cá as suas birras [AH.4, II, 158].

Dessa maneira, Bechara (2007) deixa clara sua não aceitação do uso dessa variante em situações cerimoniosas nas quais, segundo ele, deve-se usar o pronome <nós>. Confere com isso status de variante desprestigiosa à forma <a gente>, mesmo que seja visível o emprego de tal forma em palestras proferidas por brasileiros letrados, como o próprio gramático em questão, em eventos acadêmicos que, em tese, são momentos cerimoniosos.

Tal como os gramáticos anteriores, os autores Cunha e Cintra (2007) explicitam no quadro pronominal como primeira pessoa do plural apenas <nós>. Esse quadro não contempla a entrada de novos itens linguísticos no paradigma pronominal e, além disso, inclui formas em desuso no português brasileiro contemporâneo, conforme constatamos a seguir: 
Quadro 3 - Distribuição dos pronomes retos segundo Cunha e Cintra

\begin{tabular}{|c|c|c|}
\hline Pronomes Pessoais Retos & \multicolumn{2}{|c|}{} \\
\hline \multirow{2}{*}{ Singular } & $1^{\mathrm{a}}$ pessoa & eu \\
\cline { 2 - 3 } & $2^{\mathrm{a}}$ pessoa & tu \\
\cline { 2 - 3 } & $3^{\mathrm{a}}$ pessoa & ele, ela \\
\hline \multirow{2}{*}{ Plural } & $1^{\mathrm{a}}$ pessoa & nós \\
\cline { 2 - 3 } & $2^{\mathrm{a}}$ pessoa & vós \\
\cline { 2 - 3 } & $3^{\mathrm{a}}$ pessoa & eles, elas \\
\hline
\end{tabular}

Fonte: Adaptado de Cunha e Cintra (2007, p. 291)

Posteriormente, em uma seção denominada Fórmulas de Representação da $1^{a}$ Pessoa, ao final do estudo dos Pronomes de Tratamento (p.310), os autores colocam o uso de <a gente> como próprio do colóquio normal em substituição tanto de <nós> como de <eu>, salientando que nesses casos o verbo deverá ficar sempre na terceira pessoa do singular. Os seguintes exemplos são mostrados na gramática:

(04) Houve um momento entre nós/ Em que a gente não falou. (F. Pessoa, QGP, nº 270)

(05) - Não culpe mais o Barbaças, compadre! A gente só queria gastar um bocadito do dinheiro. (F. Namora, TJ,165.)

(06) - Você não calcula o que é a gente ser perseguida pelos homens. Todos me olham como se quisessem devorar-me. (C. dos Anjos, DR,41.)

Apesar de os autores citarem no prefácio da obra que almejam descrever o português contemporâneo que considere as variações existentes e que valorize a expressão oral e escrita da língua vigente, registram a forma usual <a gente> como parte do colóquio normal em observação distanciada da seção pertinente ao assunto, isto é, da apresentação do quadro de pronomes retos, de maneira que conferem à forma inovadora status de fenômeno marginal, apesar de seu largo e consagrado uso.

Como as gramáticas tradicionais prescrevem como norma um quadro pronominal que não corresponde propriamente à língua falada, verificaremos como as gramáticas descritivas e as pesquisas linguísticas sobre o fenômeno variável aqui focalizado lidam com a expressão de P4 no PB. 


\section{A Descrição das Gramáticas Científicas ou de Orientação Linguística}

As gramáticas científicas (descritivas) ou de orientação linguística buscam pesquisar e analisar um conjunto de características próprias de determinada variedade de uma língua. Segundo Travaglia (2001), nessas gramáticas há uma descrição da estrutura e do funcionamento de determinada variedade linguística, de sua forma usual em uma comunidade de fala. Verificaremos, portanto, o quadro pronominal apresentado nas seguintes gramáticas descritivas que se ocuparam da variedade culta do PB: Gramática de usos do português, de Neves (2011); Gramática Houaiss da língua portuguesa, de Azeredo (2008); Nova Gramática do Português Brasileiro, de Castilho (2010); Gramática Pedagógica do Português Brasileiro, de Bagno (2011).

Neves (2011), em sua gramática de orientação funcionalista, cogita descrever os fenômenos gramaticais do PB na língua escrita e anuncia que, apesar de seu caráter funcionalista, também registra orientações de natureza normativa:

Embora uma gramática de usos não seja, em princípio, normativa, para maior utilidade ao consulente comum a norma de usos é invocada comparativamente, de modo a informar sobre as restrições que tradicionalmente se fazem a determinados usos atestados e vivos. (NEVES, 2011, p. 14)

Na seção em que a autora trata sobre as formas dos pronomes pessoais, há um quadro em que a forma <você> e <vocês> estão inseridas como P2 e P5, mas há uma completa invisibilidade da forma <a gente> como P4.

Quadro 4 - Distribuição dos pronomes retos segundo Neves

\begin{tabular}{|c|c|c|}
\hline & Singular & Plural \\
\hline $1^{\mathrm{a}}$ pessoa & eu & nós \\
\hline $2^{\mathrm{a}}$ pessoa & tu, você & vós, vocês \\
\hline $3^{\mathrm{a}}$ pessoa & ele, ela & eles, elas \\
\hline
\end{tabular}

Fonte: Neves (2011, p. 450)

Em relação ao uso de <a gente> para expressão de P4, a autora (2011, pp. 469-470) ao final da exposição sobre os pronomes pessoais, especificamente na subseção 5.6 intitulada "Na linguagem coloquial o sintagma nominal A GENTE é empregado como pronome pessoal" (p.469), explicita que a variação que focamos neste trabalho é uma forma acolhida 
apenas no colóquio popular. Infere-se, portanto, que a autora não se persuadiu do amplo uso da forma <a gente> pelos falantes cultos do PB inclusive em contextos de fala ditos formais. A afirmativa quebra expectativas por ser a gramática de cunho descritivo cujo título põe em evidência a intenção de descrever o PB usado pelos falantes: Gramática de usos do português.

Na mesma linha de Neves, Azeredo (2008) escreveu a Gramática Houaiss da língua portuguesa com perfil descritivo, privilegiando os usos típicos da classe letrada brasileira, de maneira que a variedade escolhida como objeto de descrição é a culta, por isso ele mesmo assevera que pretende reportar-se a considerações de ordem normativa (p. 26).

Em sua descrição morfossintática, o autor inclui na lista de pronomes pessoais o termo <a gente> como expressão indicativa da primeira pessoa do plural em consonância com o pronome <nós> e justifica sua citação afirmando que os brasileiros empregam <a gente> na oralidade semiformal e informal com um valor genérico ou para referência "dêitica situacionalmente identificada" (AZEREDO, 2008, p. 176). Tal colocação demonstra que o autor situa a variação <a gente> apenas na modalidade oral informal e semiformal, como se não houvesse variação na modalidade escrita e até mesmo na oralidade de falantes cultos em situações formais.

O mesmo autor afirma que a expressão pronomes pessoais será usada como referência às formas com que se assinalam: (i) o indivíduo que fala - primeira pessoa do singular (eu); (ii) o conjunto de indivíduos em que o eu se inclui - primeira pessoa do plural (nós/a gente); (iii) o indivíduo ou indivíduos a que o eu se dirige - segunda pessoa, do singular ou do plural (tu/vós, você/vocês); (vi) O indivíduo ou coisa a que o eu se refere - terceira pessoa do singular ou do plural (ele/eles) (cf. AZEREDO, 2008, p. 175). Portanto, a forma <a gente> é listada pelo autor junto com os pronomes do cânon. Todavia, ao desenvolver o tema que se refere aos três grupos de funções dos pronomes pessoais, exclui <a gente> da lista de pronomes retos e as formas < da gente>, <com a gente> da lista de pronomes oblíquos. Segundo o autor, a classe dos pronomes pessoais é a única que apresenta formas distintas para três grupos de funções, mas ele não inclui a forma inovadora de P4 nas funções: 
Quadro 5 - Distribuição dos pronomes retos segundo Azeredo

\begin{tabular}{|l|l|}
\hline RETOS: Sujeito e predicativo & $\begin{array}{l}\text { eu / tu / você / ele / ela / nós / vós / vocês / eles } \\
\text { lelas, }\end{array}$ \\
\hline $\begin{array}{l}\text { OBLÍQUOS ÁTONOS: Funções } \\
\text { adverbiais de objeto e adjunto }\end{array}$ & $\mathrm{me} / \mathrm{nos} /$ te / vos, o / os, a / as, lhe / lhes, se \\
\hline $\begin{array}{l}\text { OBLÍQUOS TÔNICOS: Funções de } \\
\text { complemento e adjunto } \\
\text { necessariamente precedidos de } \\
\text { preposição }\end{array}$ & $\begin{array}{l}\text { mim / comigo, nós / conosco, ti / contigo, ele / ela } \\
\text { / eles / elas, vós / convosco, si/ consigo }\end{array}$ \\
\hline
\end{tabular}

Fonte: Adaptado de Azeredo (2008, p. 175)

Já Castilho (2010) apresenta seu quadro pronominal a partir de dados coletados pelos inquéritos do Nurc (Projeto da Norma Urbana Oral Culta) no qual exibe o termo <a gente> concorrendo com a forma <nós> nos mesmos contextos, o que confirma a paridade entre os termos no PB, "sobretudo na modalidade falada, com fortes consequências na estrutura sintática da língua" (CASTILHO, 2011, p. 477). Conforme colocação do autor, a variedade brasileira atual apresenta o seguinte quadro de pronomes pessoais:

Quadro 6 - Distribuição dos pronomes retos segundo Castilho

\begin{tabular}{|c|c|c|c|c|}
\hline \multirow[t]{2}{*}{ essoa } & \multicolumn{2}{|c|}{ PB Formal } & \multicolumn{2}{|c|}{ PB Informal } \\
\hline & sujeito & complemento & Sujeito & complemento \\
\hline $1^{\mathrm{a}}$ pessoa sg. & $\mathrm{eu}$ & me, mim, comigo & eu, a gente & $\begin{array}{l}\text { eu, me, mim, Prep. } \\
+ \text { eu, mim }\end{array}$ \\
\hline $2^{\mathrm{a}}$ pessoa $\mathrm{sg}$. & $\begin{array}{l}\text { tu, você, o senhor, } \\
\text { a senhora }\end{array}$ & $\begin{array}{l}\text { te, ti, contigo, Prep +o } \\
\text { senhor, com a senhora }\end{array}$ & você/ocê/tu & $\begin{array}{l}\text { você/ocê/cê, te, ti, } \\
\text { Prep + você/ocê } \\
(=\text { docê }, \text { cocê })\end{array}$ \\
\hline $3^{\text {a }}$ pessoa sg. & ele, ela & o/a, lhe, se, si, consigo & ele/ei, ela & $\begin{array}{l}\text { ele, ela, lhe, } \\
\text { Prep + ele, ela }\end{array}$ \\
\hline $1^{\mathrm{a}}$ pessoa pl. & nós & nos conosco & a gente & $\begin{array}{l}\text { a gente, Prep }+a \\
\text { gente }\end{array}$ \\
\hline $2^{\mathrm{a}}$ pessoa pl. & $\begin{array}{l}\text { vós, os senhores, } \\
\text { as senhoras }\end{array}$ & $\begin{array}{l}\text { vos, convosco, Prep + } \\
\text { os senhores, as } \\
\text { senhoras }\end{array}$ & vocês/ocês/cês & $\begin{array}{l}\text { vocês/ocês/cês, } \\
\text { Prep + vocês/ocês }\end{array}$ \\
\hline $3^{\text {a }}$ pessoa pl. & eles, elas & $\begin{array}{l}\text { os/as, lhes, se, si, } \\
\text { consigo }\end{array}$ & eles/eis, elas & $\begin{array}{l}\text { eles/eis, elas, } \\
\text { Prep + eles/eis, } \\
\text { elas }\end{array}$ \\
\hline
\end{tabular}

Fonte: Castilho (2010, p. 477)

Para Castilho, a forma <nós> tem sido substituída pelo sintagma nominal <a gente>, como percebemos nos exemplos abaixo, retirados do mesmo autor (2010, p. 478):

A gente não está sabendo bem como sair desta. 
(08) Nós rimos muito ontem à noite, e aí a gente começamos a se entender.

(09) Nós tem uma sinuquinha lá que nós fizemos, a gente não se fala legal.

Note-se que a construção do exemplo (08), em que a concordância verbal com <a gente> é feita de acordo com a variante <nós>, é fortemente estigmatizada pelos falantes cultos do PB, até mesmo em ambientes informais. Também no exemplo (09) o mesmo estigma aparece em relação à concordância do verbo ter com o pronome <nós>.

Tal como os linguistas vistos anteriormente, o autor considera <a gente $>$ apenas no registro informal e reforça que o fenômeno ocorre sobretudo na modalidade oral. Subtende-se que o gramático em questão considera pouco viável a ocorrência da forma <a gente> na fala em situações formais, o que contraria o resultado de várias pesquisas atuais que constataram largo emprego da variante inovadora em registros orais de muitos indivíduos cultos em situações em que se exigiria a variedade de prestígio, tal como palestras de eventos acadêmicos.

Por sua vez, Bagno (2011), que é um crítico do tradicional ensino de língua portuguesa impregnado de preconceitos sociais e linguísticos, propõe novos termos e conceitos para maior precisão na análise da realidade sociolinguística brasileira. Ele tem uma linha bem radical em relação à padronização da língua e aos preconceitos linguísticos dela decorrentes. Em sua Gramática Pedagógica do Português Brasileiro, busca descrever o funcionamento do português contemporâneo e, ao expor o quadro pronominal, ele reconhece o termo <a gente> como indicador da primeira pessoa do plural em conjunto com <nós>.

O autor ainda enfatiza que, na posição de sujeito do PB contemporâneo, a preferência é pelo termo <a gente>, principalmente por jovens, tendo esse uso se tornado cada vez mais abrangente. Além de fazer uma descrição do PB quanto ao uso dos pronomes pessoais, Bagno (2011) também tece críticas às escolas e livros didáticos que, ao referirem-se ao fenômeno <a gente> como usado em situações de menos monitoramento, conferem status de prescrição e não de descrição ao fenômeno (cf. BAGNO, 2011, p. 743). Para o estudioso, os brasileiros já passaram a usar <a gente> mesmo em situações mais monitoradas, causando mudanças nas variedades urbanas de prestígio que agora comportam a ascensão de uma nova classe média.

Ademais, o autor chama a atenção para o fato de que as variedades urbanas de prestígio também costumam conjugar formas verbais de <nós> para fazer referência a <a gente> na posição de sujeito, como no exemplo do NURC mencionado pelo autor: 
[...] e então nós ficávamos jogando... aí que eu aprendi a jogar buraco... e a gente gostou tanto que ficava todo o dia jogando... lembro que nós passamos no hotel... mas a gente não jogava a dinheiro nada... só assim na brincadeira... então passamos tinha umas velhas uma senhoras de mais idade e nos viram... sempre jogando...quando nós passamos elas disseram assim "essas viciadas" ((risos)) como se a gente jogasse ah... muito...(BAGNO, 2011, p. 744).

Diante da análise de diferentes gramáticas descritivas, concluímos que, embora <a gente> seja natural aos falantes das mais diversas classes sociais, a variante ainda sofre resistência para sua inclusão no quadro de pronomes da modalidade escrita. Percebe-se que as gramáticas descritivas até trazem maiores informações a respeito do uso da forma inovadora como pronome de primeira pessoa do plural, mas costumam situar esse item pronominal como pertencente ao registro informal do $\mathrm{PB}$, como se não fosse possível sua ocorrência em situações ditas formais. Na verdade, esse item linguístico pode ocorrer sim na fala em situações formais, mas não no registro escrito representativo de eventos do polo de [+ letramento] do contínuo (cf. BORTONI-RICARDO, 2004). Portanto, há resistência na modalidade escrita padronizadora, mas não na fala culta, independentemente se é informal ou formal, conforme será demonstrado na próxima seção que trata das pesquisas sociolinguísticas sobre a variação nós/a gente no PB.

\section{As Pesquisas Sociolinguísticas Sobre Variação Nós/ A gente no PB}

Muitas são as pesquisas sociolinguísticas que se ocuparam do uso da forma <a gente> em concorrência com <nós> na variedade brasileira do português. Assim, faremos um levantamento de trabalhos representativos sobre o fenômeno da variação na expressão de P4 em diferentes regiões brasileiras.

Uma das primeiras pesquisadoras a investigar a alternância entre pronomes de primeira pessoa do discurso no plural dentro do PB foi Omena $(1986,1996)$. A pesquisadora fez a análise da fala de informantes cariocas não cultos com base em uma amostra do banco de dados do Projeto Censo da Variação Linguística do Estado do Rio de Janeiro (CENSO). Foram utilizadas 64 entrevistas coletadas em 1980, nas quais estavam representadas três faixas etárias (15 a 25 anos, 26 a 49 anos e 50 anos ou mais), os dois gêneros (feminino e masculino) e três níveis de escolarização $\left(1^{\mathrm{a}}\right.$ a $4^{\mathrm{a}}$ séries ou antigo primário; $5^{\mathrm{a}}$ a $8^{\mathrm{a}}$ séries, o que era conhecido como ginásio, e $2^{\circ}$ grau, hoje Ensino Médio). Ela levantou a hipótese de que a necessidade de contrapor, na primeira pessoa do discurso no plural, uma referência 
precisa a uma imprecisa pode ter sido a causa da origem do fenômeno <a gente> como expressão de P4. A autora investigou o uso de <a gente> em lugar de <nós> em várias funções sintáticas e comprovou os diferentes estágios dessa mudança em que a forma variante ocupa o lugar do pronome canônico. Vejamos alguns exemplos retirados de Omena (1996, pp.189-187):

(10) A gente encosta ela nas pedras, joga o equipamento de mergulho tudo, sem a equipe. (sujeito)

(11) Ele já não conhece a gente, fica com medo, sabe? (objeto direto)

(12) Aí, inclusive, a menina que estava de plantão nesse dia é amiga da gente. (adjunto adnominal)

(13) Aí a minha mãe veio abrir a porta pra gente. (objeto indireto)

(14) Eles falam bem diferente da gente. (complemento nominal)

(15) Quem faz a moda é a gente. (predicativo do sujeito)

A tabela seguinte especifica os resultados encontrados pela autora:

Tabela1 - Frequência do uso de $a$ gente em todas as funções

\begin{tabular}{|c|c|c|c|c|c|c|}
\hline Fatores & \multicolumn{2}{|c|}{ Todos } & \multicolumn{2}{c|}{ Adultos } & \multicolumn{2}{c|}{ Crianças } \\
\hline & \multicolumn{2}{|c|}{ Frequência } & \multicolumn{2}{c|}{ Frequência } & \multicolumn{2}{c|}{ Frequência } \\
\hline adj. adv. & $57 / 68$ & $84 \%$ & $37 / 48$ & $77 \%$ & $20 / 20$ & $100 \%$ \\
\hline complemento & $199 / 277$ & $72 \%$ & $133 / 204$ & $65 \%$ & $66 / 73$ & $90 \%$ \\
\hline sujeito & $1979 / 2701$ & $73 \%$ & $1454 / 2063$ & $70 \%$ & $525 / 638$ & $82 \%$ \\
\hline adj. adn & $35 / 253$ & $14 \%$ & $26 / 210$ & $12 \%$ & $9 / 43$ & $21 \%$ \\
\hline total & $2270 / 3299$ & $69 \%$ & $1650 / 2525$ & $65 \%$ & $620 / 774$ & $80 \%$ \\
\hline
\end{tabular}

Fonte: Omena. (1996, p. 191)

De acordo com a tabela, o total geral da forma <a gente $>$ apresenta-se num patamar de $69 \%$ em relação ao uso de <nós>. No âmbito geral, por função sintática, a entrada da forma inovadora é maior na função de adjunto adverbial, depois na de sujeito e de complemento, já começando a atingir o uso possessivo na função de adjunto adnominal, embora o uso da forma $\langle$ nosso $\rangle$, correspondente ao tradicional pronome de primeira pessoa do plural, ainda seja largamente majoritário. Com relação aos dados de adultos e de crianças analisados 
separadamente, percebeu-se que o uso de <a gente> apresenta índices mais elevados na fala infantil em todas as funções, chegando a ser categórico na função de adjunto adverbial, o que sugere serem os jovens o grupo que mais favorece a implementação de uma possível mudança.

A linguista ainda observou que <nós> e <a gente> têm em comum os traços de $\left[+1^{\mathrm{a}}\right.$ pessoa gramatical] e [+ pluralidade], o que permite a alternância no uso, podendo ainda as duas formas indicar, em determinados contextos, tanto a referência à primeira pessoa do plural quanto à primeira pessoa do singular.

Para analisar as variantes <nós> e < a gente> na função de sujeito, a mesma autora investigou variáveis linguísticas ou fatores estruturais, tais como disposição das formas na sequência do discurso, saliência fônica e indeterminação do referente.

O primeiro fator estrutural consiste no uso pela primeira vez na sequência discursiva de uma variante de P4 para nomear um referente, ou seja, aquela que serve de expressão de primeira referência para indicar P4. Segundo a autora, quando já houve uma referência anterior, esta pode ter sido feita, usando-se uma das formas de referência da primeira pessoa do plural, quais sejam, <a gente>, <nós>, verbo com desinência de terceira pessoa do singular, verbo com desinência de primeira pessoa do plural. O referente nomeado pode também ter sido igual ou diferente do anterior, como vemos no exemplo a seguir extraído da amostra da autora (p. 194):

(16) Meu marido tinha medo dela ser infeliz, tanto que, com ela com vinte e quatro horas de casada, nós fomos, lá, né?...A gente, dia sim, dia não ia na casa dela...Por que $a$ gente que é mãe, quer sempre o melhor pro filho.

No exemplo acima, a primeira referência é <nós> para nomear "eu e meu marido "e em uma segunda referência às mesmas pessoas o falante usou <a gente>. Já na terceira referência houve a generalização do uso de <a gente> que passou a significar todas as mães.

Os resultados gerais desse fator estrutural indicam ser a forma <a gente> a preferida, tanto para a primeira referência $(70 \%)$ quanto para a sequência do discurso, com altos índices com referente igual $(93 \%)$ e com referente diferente $(84 \%)$.

Em relação ao segundo fator estrutural, a saliência fônica, o que Omena registra é que, nos níveis de menor diferenciação fônica, a forma <a gente> teve mais ocorrências, ao contrário de contextos com maior saliência fônica entre as formas verbais (p. ex. somos/é) em que o emprego dessa variante foi menos frequente. 
Por fim, no que diz respeito à indeterminação do referente, há uma diferenciação no emprego de <a gente> e <nós> em relação a um referente mais restrito ou mais genérico. Quando o falante se refere a ele mesmo e mais o interlocutor, ou seja, referência específica, determinada, usa principalmente o pronome <nós>. Já no uso genérico e impessoal da referência objetivando indeterminá-la, a variante <a gente> é a preferida pelo falante.

Entre os fatores sociais analisados por Omena (1996), a faixa etária dos informantes foi considerada relevante. Os resultados encontrados evidenciaram o uso da forma inovadora na preferência dos mais jovens, tendo as crianças de 7 a 14 anos apresentado uma frequência de $90 \%$, enquanto os jovens de 15 a 25 anos revelaram um índice de $87 \%$, o que poderia indicar um processo de mudança em curso. De acordo com a autora, tais números "indicam que os falantes nascidos a partir de aproximadamente 1960 usam bem mais a forma <a gente>" (OMENA, 1996, p. 312). Outro fator social influenciador foi a escolaridade. Segundo a autora, o contato com a escola influenciou no uso da forma pronominal tradicional <nós>, no entanto, ao concluírem o segundo grau (hoje ensino médio), os falantes passaram a utilizar mais a forma <a gente>, fenômeno que, segundo a autora ponderou, carece de maiores investigações.

Por sua vez, Lopes $(1993,2003,2007)$ trouxe relevante discussão sobre a mudança no quadro pronominal do PB por meio de pesquisas que comprovaram a ascensão do uso de <a gente> na variedade brasileira, tendo apresentado similaridades com as pesquisas de Omena (1986). Segundo a pesquisadora ora em foco, tal fenômeno ocorreu não só na modalidade oral como também nos textos escritos que reproduzem situações dialógicas ou de menor grau de formalidade (cf. LOPES, 2007).

Na pesquisa realizada em 2003, Lopes investigou um corpus proveniente do Arquivo Sonoro do Projeto Nurc/Brasil (Norma Urbana Culta), constituído por entrevistas do tipo DID (diálogo informante e documentador), coletadas na década de 70 , em três capitais brasileiras: Salvador (Região Nordeste), Porto Alegre (Região Sul) e Rio de Janeiro (Região Sudeste).

Todos os dados coletados incluíram apenas falantes já graduados tidos como usuários da modalidade culta. Os informantes foram distribuídos em três faixas etárias: de 25 a 35 anos, de 36 a 55 anos e acima de 55 anos. O objetivo foi traçar um mapa das condições linguísticas e sociais que privilegiavam uma ou outra escolha. Os fatores sociais como faixa etária, sexo, localidade foram considerados. Quanto à localidade, o Rio de Janeiro mostrou-se mais favorável à mudança com maior uso de <a gente>, enquanto Salvador e Porto alegre foram mais conservadores. 
No que diz respeito à faixa etária, foi observado que os mais velhos preferiam a variante padrão, enquanto os informantes do grupo intermediário mostraram paridade de uso entre as variantes, sendo os mais jovens os que mostraram preferência pela forma inovadora. Quanto ao fator sexo, as mulheres demonstraram mais tendência, em algumas cidades, ao uso da forma <a gente $>$.

Ainda no mesmo trabalho de 2003, a autora ora em questão comparou os resultados de dois trabalhos com amostras de fala carioca diferenciadas em termos de grau de escolaridade: nível superior (amostra do Projeto Nurc/RJ) e nível médio (amostra do Projeto Peul-RJ Programa de Estudos sobre o Uso da Língua). A análise foi feita baseada no comportamento da comunidade a partir do confronto de duas décadas de cada projeto anos 70 e 90 e anos 80 e 2000, respectivamente. Na pesquisa, Lopes apurou que todas as amostras convergem para a substituição de <nós> por <a gente>, fenômeno que se concretiza progressivamente no decorrer dos anos tanto entre os falantes cultos quanto entre os não cultos no Rio de Janeiro.

No confronto das duas décadas em relação à faixa etária, tanto na amostra do projeto Nurc quanto na do Peul, a pesquisadora (2003) percebeu que houve crescimento na primeira faixa etária configurada por jovens até 25 anos nas décadas de 70 (84\%) e 90 (92\%), o que poderia assinalar uma mudança em progresso, porém a retração no uso da forma inovadora pelos informantes cultos de mais idade da década de 70 (26\%) para a de 90 (19\%) inibe essa assertiva.

No que diz respeito ao fator sexo, a pesquisadora observou que os homens (69\%) preferem o emprego da forma padrão, enquanto as mulheres (49\%) usam mais a forma inovadora.

Entre os grupos de fatores linguísticos levantados por Lopes, chamam atenção a saliência fônica e o traço semântico de indeterminação.

A saliência fônica foi um fator relevante na explicação para maior uso de <a gente> no falar carioca, visto que essa variante apareceu utilizada preferencialmente com as formas verbais que apresentam menor grau de saliência fônica (79\%), como o presente do indicativo (fala/falamos). O oposto se verificou com as formas verbais que exibem maior diferenciação fônica entre P3 e P4, como o pretérito perfeito do indicativo (falou/ falamos), em que se deu maior uso de <nós> $(64 \%)$.

No que diz respeito ao fator traço semântico, a linguista constatou que, quando se trata de referência genérica ou indeterminada, <a gente> exibe índice ainda mais alto de frequência $(93 \%)$ do que em contexto de referência específica ou determinada (59\%).

Ela ainda cita os resultados encontrados na pesquisa de Omena (2003) em que <a 
gente> tem o uso preferencial tanto no contexto de referência determinada quanto indeterminada, mesmo entre os falantes cultos. Segundo Lopes, tais resultados podem sugerir a generalização de < a gente >para todos os contextos como forma quase que obrigatória.

Em seu trabalho, Machado (1995), com base nos dados do arquivo sonoro do projeto Aperj (Atlas Etnolinguístico dos Pescadores do Estado do Rio de Janeiro), pesquisou o uso de <nós> e <a gente> na fala de informantes com baixa escolaridade. Foram analisadas 2.972 ocorrências, retiradas de 72 entrevistas com pescadores. Os informantes eram do sexo masculino, analfabetos ou com o mínimo de escolarização, naturais de doze localidades pesqueiras na parte norte do Estado do Rio de janeiro. O corpus foi estratificado de acordo com três faixas etárias: 18 a 35 anos, 36 a 55 anos e 56 a 75 anos.

A produtividade geral de uso das formas registrou índices bastante altos com relação ao pronome inovador $(72 \%)$, ao passo que a produtividade do pronome padrão foi reduzida (28\%) entre os pescadores, o que parece indicar avançado processo de substituição de <nós> por <a gente> quando se tem em vista tal grupo.

O peso relativo para uso de <a gente> na amostra foi de 0.72 , levando-se em consideração tanto sujeitos nulos quanto sujeitos expressos. Destaca-se nessa investigação a irrelevância do fator escolaridade, normalmente apontado como significativo para a variação <nós> e <a gente>. Por conseguinte, o pesquisador verificou que tanto os informantes analfabetos quanto os informantes com alguma escolaridade não só estão expostos à variação de <nós> e <a gente>, como fazem uso destas duas formas pronominais.

Por outro lado, a localidade teve influência no sentido de favorecer ou não o uso da forma inovadora. Segundo Machado (1995), a distribuição geográfica das variantes apresentou-se bem marcada: houve favorecimento de <a gente> nas localidades de Atafona, Gargaú, Guaxindiba (localizadas no município de Campos), Itaperuna e São João da Barra; e predomínio de <nós> em São Fidélis, Cambuci, Barra de Itabapoana, Farol de São Tomé e, principalmente, em Itaocara. A faixa etária também se mostrou bastante influente na alternância dos pronomes: registrou-se o favorecimento de <a gente> entre os mais jovens (0.70), havendo diminuição nas faixas etárias subsequentes e chegando a índices de restrição entre os idosos (0.40). Esse estudo sociolinguístico, portanto, vem confirmar a tendência geral de uso de <a gente> no PB.

Em Maia (2003), encontramos o estudo da alternância entre <nós> e <a gente> no dialeto mineiro. $\mathrm{O}$ autor utilizou duas amostras, sendo uma constituída por doze entrevistas realizadas com informantes do município de Pombal/Mariana (MG); e a outra formada por entrevistas realizadas com indivíduos de Belo Horizonte. Todos os entrevistados têm pouca 
escolaridade ou são analfabetos. As localidades refletem o espaço rural e o urbano, respectivamente. Nas duas amostras em conjunto, $53 \%$ dos dados eram da forma inovadora <a gente>, suplantando ligeiramente o uso padrão.

Em relação à distribuição geográfica das variantes, Maia observou que o espaço urbano prestigia o novo pronome (70\%), enquanto a área do meio rural é mais conservadora no uso desse mesmo pronome (35\%). A diferença entre a zona urbana e rural aponta para uma possível explicação de um maior conservadorismo linguístico em Minas Gerais.

Do mesmo modo, Rocha (2009) pesquisou o falar mineiro, desta vez na capital Belo Horizonte, através de uma amostra já pronta, constituída por entrevistas sociolinguísticas colhidas durante o Projeto Descrição Sócio-histórica do Português de Belo Horizonte. Em 615 dados de referência à primeira pessoa do plural, foram aferidas $329(63 \%)$ ocorrências de <a gente> e apenas 198 (37\%) do pronome pessoal <nós> em posição de sujeito, tendo a variante inovadora superado o emprego do pronome canônico em todos os estratos sociais.

Em Vitória- ES, Mendonça (2010) averiguou o uso de <nós> e <a gente> na fala capixaba. Ele utilizou o banco de dados do Projeto do Português falado em Vitória (PortVix), composto por 46 entrevistas, das quais utilizou 40. Tal corpus encontra-se organizado por sexo (feminino e masculino), faixa etária ( 7 a 14 anos; 15 a 25 anos; 26 a 49 anos; 50 anos ou mais) e escolaridade (ensino fundamental, ensino médio e ensino universitário). Foram obtidos 1.745 dados de referência à primeira pessoa do plural, tendo-se observado que falantes nativos de Vitória preferem a forma <a gente> (71\%), havendo menor incidência no uso da forma padrão (29\%).

A constatação do pesquisador em relação à faixa etária dos vitorienses é que os mais jovens preferem o uso da forma inovadora, seguindo a tendência do restante do país: $85 \%$ de 7 a 14 anos; $83 \%$ de 15 a 25 anos; $58 \%$ de 26 a 49 anos e $56 \%$ a partir de 50 anos.

A pesquisa ainda mostrou, por meio dos pesos relativos, que as mulheres usam mais a forma $<$ a gente $>(0.60)$, enquanto os homens preferem o pronome tradicional $(0.35)$, fato que também foi percebido por outros pesquisadores.

Quanto à variável social escolaridade, o pesquisador apurou que os falantes vitorienses de nível fundamental e médio usam um pouco menos a forma <a gente> $(0.48$ ambos $)$ em comparação com os falantes universitários (0.55). Mendonça (2010) fez também um estudo analítico das ocorrências da forma <a gente> competindo com o pronome <nós> em várias cidades nas quais o fenômeno foi pesquisado, comparando os resultados dessas pesquisas com os da sua em Vitória. O estudo comparativo baseia-se nas seguintes pesquisas de fala: Rio de Janeiro (OMENA, 1996 e 2003); João Pessoa (FERNANDES, 1996); Florianópolis (SEARA, 
2000); Jaguarão e Pelotas (BORGES, 2004) e Porto Alegre (ZILLES, 2007). A comparação consolida a proposição de que por todo o Brasil os falantes estão favorecendo a forma <a gente> em substituição ao pronome <nós>, conforme ilustra o gráfico a seguir:

Gráfico 1 - Percentuais de uso da forma <a gente> nos trabalhos consultados

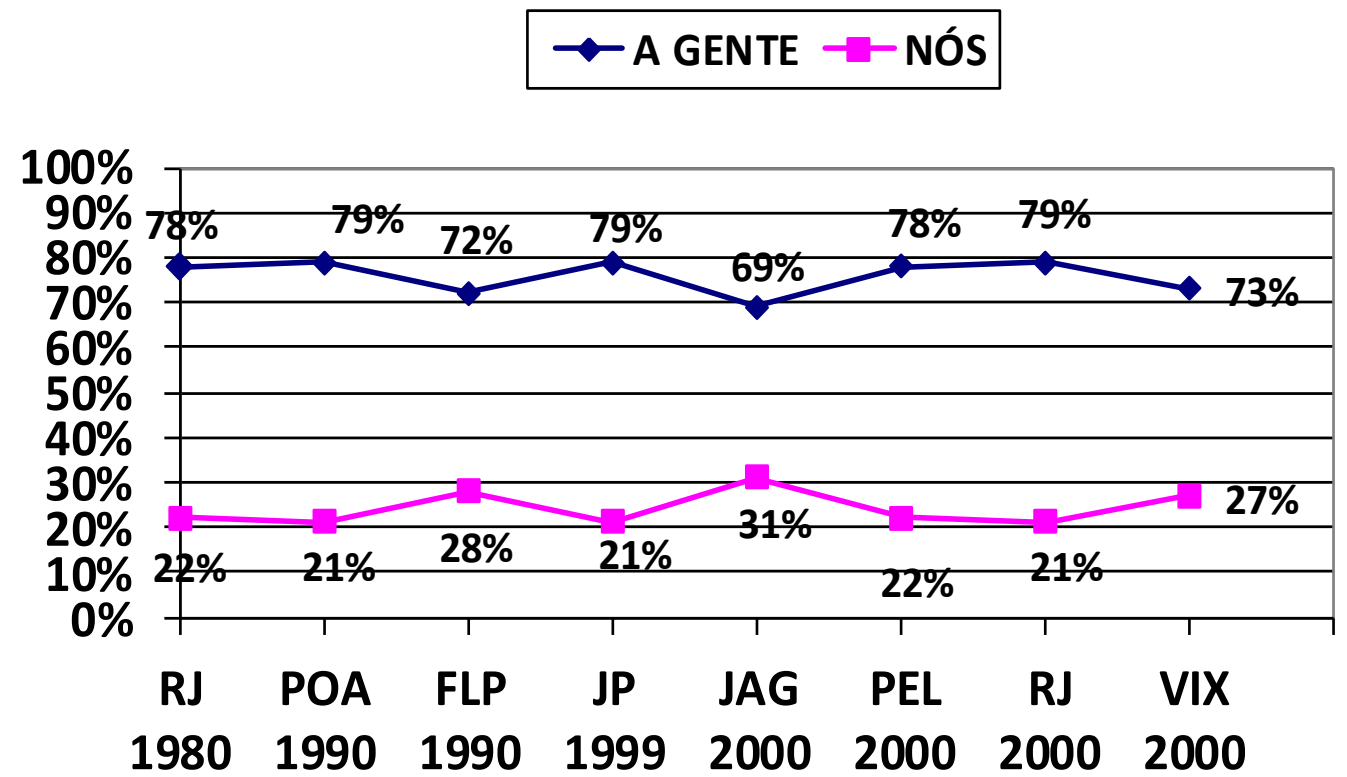

Fonte: Mendonça (2010)

O pesquisador ressalta que a forma <a gente> é admitida tanto para o papel de sujeito quanto para a função de complemento verbal, o que não ocorre com a forma <nós> que atende muito bem à função de sujeito, mas não a de complemento, sobretudo o objeto direto. O autor também constata que, por não ser estigmatizada, a forma <a gente> já se faz presente em todos níveis de escolaridade e classes sociais.

Por fim, Vianna (2011) também fez um levantamento das pesquisas sobre a inserção de <a gente> no quadro pronominal e concluiu que entre os fatores linguísticos relevantes e pertinentes para a ocorrência dessa variante estão os seguintes: o paralelismo formal e discursivo; o traço semântico de [+ indeterminação] do referente; o tempo verbal e a saliência fônica. Já entre os grupos de fatores sociais que normalmente são relevantes para o fenômeno estão a faixa etária, gênero/sexo, escolaridade e localidade. A pesquisadora levantou dados das pesquisas feitas nos últimos 25 anos em várias capitais brasileiras e observou que o pronome inovador suplanta o uso do pronome tradicional em todas, porém com diferenças entre as capitais em termos de celeridade na implantação de <a gente>. Em João Pessoa (JPA), por exemplo, observou-se a maior produtividade: a variante inovadora representou 
79\% das ocorrências de P4 (Amostra VALPB). Dentro da região Sudeste, também há diferenças entre as capitais. Constatou-se que em Belo Horizonte $(\mathrm{BH})$ há um comportamento ligeiramente mais conservador do que o observado em Vitória (VIX) - respectivamente, 62\% e $71 \%$. Por sua vez, há semelhança entre os resultados obtidos em Vitória (71\%) e a distribuição verificada em Porto Alegre (POA), com $70 \%$ de uso da forma inovadora. Diferentemente, a cidade de Curitiba (CWB) mostra-se a mais conservadora de todas as capitais pesquisadas, exibindo os índices mais baixos de uso de <a gente> (54\%).

Ao fazer o levantamento do comportamento de falantes com menor grau de escolaridade nas diferentes pesquisas sobre o fenômeno variável aqui focalizado, a mesma autora observou resultados semelhantes nas diversas capitais. A produtividade de <a gente> no Rio de Janeiro (RIO) é da ordem de $79 \%$, de maneira semelhante ao que se observa em Belo Horizonte $(\mathrm{BH})$ com $70 \%$ e Florianópolis (FLN) com 72\%. A cidade de Curitiba (CWB), novamente, mostrou-se a mais conservadora, apresentando o menor índice de emprego de <a gente> com $64 \%$ de ocorrências.

Assim, através dos estudos comparativos entre diversas pesquisas, Vianna concluiu que o processo de substituição de <nós> por <a gente> no PB se encontra em tão avançado estágio na modalidade oral, que tal fenômeno é amplamente caracterizado como mudança linguística. A pesquisadora traçou um mapa que ilustra as regiões do Brasil em que o fenômeno foi investigado. A figura a seguir exibe um mapa que, apesar de estar um tanto defasado em razão de outros trabalhos acadêmicos sobre o fenômeno realizados após 2011, serve para ilustrar a pesquisa sobre o uso de <a gente> na variedade brasileira do português. 
Figura 1 - Mapa ilustrativo das regiões do Brasil em que os processos de substituição de $<$ nós> por <a gente> foi investigado.

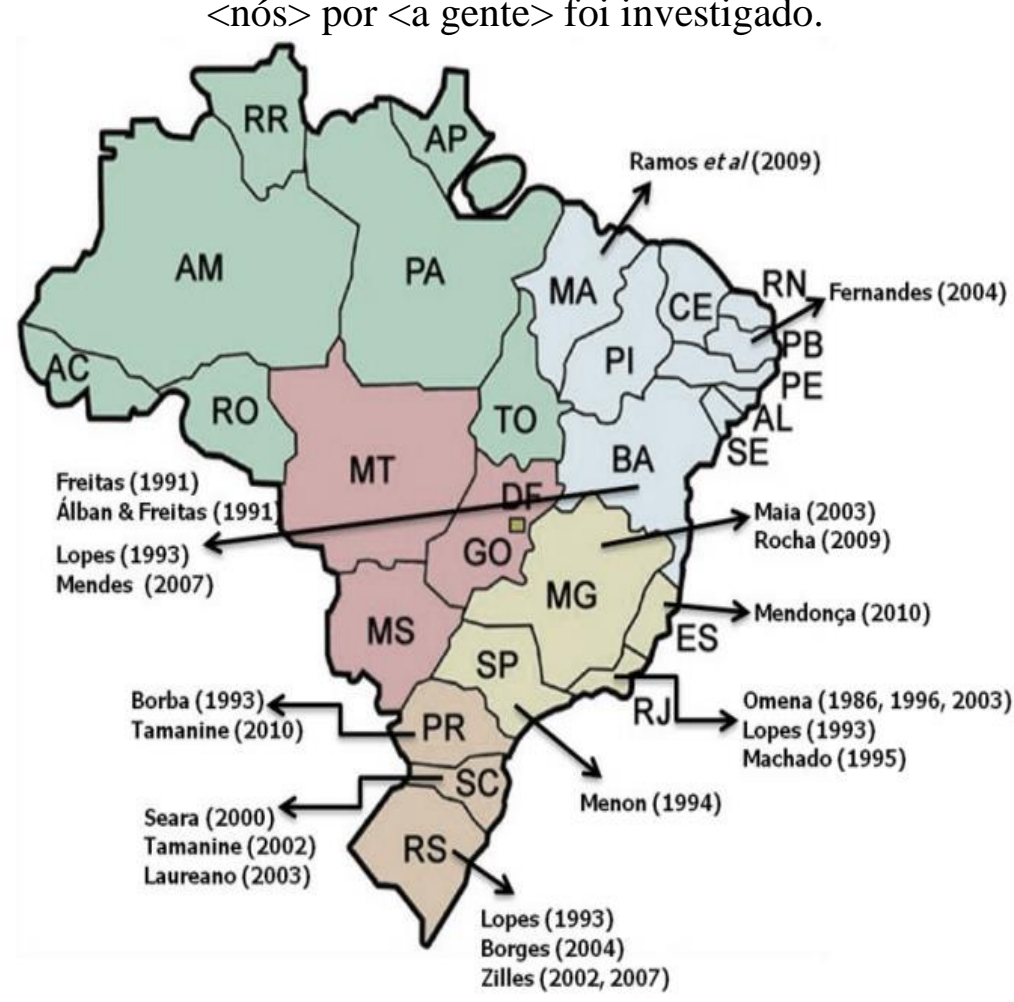

Fonte: Vianna (2011)

\section{Considerações finais}

O presente artigo tencionou como apresentar a descrição do quadro pronominal do português, observando o tratamento dado pelas gramáticas normativas de língua portuguesa ao assunto em contraste com o que aparece nas gramáticas de orientação linguística e concluindo com um levantamento dos resultados de pesquisas sociolinguísticas sobre a variação na expressão da primeira Pessoa do plural. Ao se conhecer mais profundamente essas abordagens torna-se possível uma contribuição ao ensino de língua portuguesa no que diz respeito ao conhecimento da abordagem da variação linguística em sala de aula a partir de um trabalho sistemático com um fenômeno variável, qual seja, a alternância nós/ a gente.

Diante da análise de diferentes gramáticas normativas, conclui-se que, embora <a gente> seja natural aos falantes das mais diversas classes sociais, a variante ainda sofre resistência para sua inclusão no quadro de pronomes da modalidade escrita. Já nas gramáticas descritivas há maiores informações a respeito do uso da forma inovadora como pronome de primeira pessoa do plural, todavia, o fenômeno aparece, de modo geral, como pertencente ao registro informal do PB, como se não fosse possível sua ocorrência em situações ditas formais. 
No entanto, diante das abordagens apresentadas pelas pesquisas sociolinguísticas, podemos perceber que esses estudos variacionistas apontaram as seguintes congruências: (i) os falantes jovens usam mais a forma <a gente>; (ii) as mulheres acolhem mais a inovação na maioria das cidades; (iii) o maior grau de escolaridade não coíbe o uso da forma inovadora. Por outro lado, percebeu-se que há uma variação estável entre a forma tradicional e a forma inovadora não estigmatizada. Portanto, infelizmente, as gramáticas normativas que servem de base ao ensino não descrevem o quadro pronominal do PB de acordo com tais pesquisas e desprestigiam o falar usual dos brasileiros e as gramáticas descritivas, de modo geral, conferem ao fenômeno cunho marginal

Percebeu-se com esta pesquisa a importância da ação das instituições de ensino não só para a aprendizagem da norma prescrita pela tradição gramatical, como também para a possibilidade de admitir e contextualizar o uso de outras variantes usadas pelos falantes. Tais variantes não devem ser discriminadas, sendo até mesmo desejáveis em determinados pontos do contínuo de oralidade-letramento (cf. BORTONI-RICARDO, 2004), como é o caso da expressão de $\mathrm{P} 4$ representada por <a gente>, que tem ampliado a cada dia sua abrangência, infiltrando-se até mesmo na escrita. Todo falante deve ter o conhecimento necessário para transitar entre as diferentes variedades, de modo a atender aos diversos eventos comunicativos, mediados quer pela fala, quer pela escrita.

\section{REFERÊNCIAS}

AZEREDO, J. C. de Gramática Houaiss da língua portuguesa. 2. ed. São Paulo: Publifolha, 2008.

BAGNO, M. Gramática pedagógica do português brasileiro. São Paulo: Parábola Editorial, 2011.

BECHARA, E. Moderna gramática portuguesa. 37. ed. rev., ampl. e atual. conforme o novo Acordo Ortográfico. Rio de Janeiro: Nova Fronteira, 2007.

BORTONI-RICARDO, S.M. Educação em Língua Materna: a sociolingüística na sala de aula. São Paulo: Parábola, 2004.

CASTILHO, A. T. de. Nova gramática do português brasileiro. São Paulo: Contexto, 2010

CUNHA, C. F.; Cintra, L. Nova gramática do português contemporâneo. Rio de Janeiro: Nova Fronteira, 1985.

FARACO, C. A. Norma culta Brasileira: desatando alguns nós. São Paulo: Parábola Editorial, 2008. 
LOPES, C.R.S. Nós e a gente no português falado culto do Brasil. Rio de Janeiro: Faculdade de Letras/UFRJ. Dissertação de Mestrado em Língua Portuguesa. Universidade Federal do Rio de Janeiro, Rio de Janeiro, 1993.

LOPES, C.R.S. A inserção de 'a gente' no quadro pronominal do português.

Frankfurt/Madri: Vervuert/Iberoamericana, v. 18, 2003.

LOPES, C.R.S. A gramaticalização de a gente em português em tempo real de longa e de curta duração: retenção e mudança na especificação dos traços intrínsecos. Fórum Linguístico, v. 4, n. 1. Florianópolis, jul. 2004. p. 47-80.

LOPES, C.R.S. A gramaticalização de a gente em português em tempo real de longa e de curta duração: retenção e mudança na especificação dos traços intrínsecos. Fórum Linguístico, v. 4, n. 1, p. 47-80, 2007.

MACHADO, M. S. Sujeitos pronominais "nós" e "a gente": variação em dialetos populares do norte fluminense. Dissertação (Mestrado em Língua Portuguesa) - Universidade Federal do Rio de Janeiro, Rio de Janeiro, 1995.

MAIA, F. P. S. A variação "nós" / "a gente" no dialeto mineiro: investigando a transição. 2003. Dissertação (Mestrado em Estudos Linguísticos) - Universidade Federal de Minas Gerais, Belo Horizonte, 2003.

MENDONÇA, A. K. Nós e a gente em Vitória: análise sociolinguística da fala capixaba. 2010. Dissertação (Mestrado em Estudos Linguísticos) - Universidade Federal do Espírito Santo, Vitória, 2010.

OMENA, N. P. A referência variável da primeira pessoa do discurso no Plural. In: NARO, A. J. et al. Relatório Final de Pesquisa: Projeto Subsídios do Projeto Censo à Educação, Rio de Janeiro, UFRJ, 1986.

OMENA, N. P. As influências sociais na variação entre nós e a gente na função de sujeito. In: OLIVEIRA E SILVA, G. M.; SCHERRE, M. M. P. Padrões Sociolinguísticos: análises de fenômenos variáveis do português falado na cidade do Rio de Janeiro. Rio de Janeiro: Tempo Brasileiro, p. 309-323, 1996

OMENA, N. P. A referência à primeira pessoa do plural: variação ou mudança? In: PAIVA, M. C.; DUARTE, M. E. L. (Org.). Mudança linguística em tempo real. Rio de Janeiro: Contracapa, 2003.

ROCHA, F. C. F. A alternância nos pronomes pessoais e possessivos do português de Belo Horizonte. Dissertação de Mestrado em Linguística e Língua Portuguesa, Belo Horizonte, Faculdade de Letras/PUC-MG, 2009

ROCHA LIMA, C. H. Gramática normativa da língua portuguesa. J. Olympio, 2008 [1972].

SILVA, C. de O.; SILVA, E. G.de O.; ARAÚJO, L. A. M.; OLIVEIRA, T. A. Tecendo Linguagens. 4 eds. IBEP, 2015 
VIANNA, J. B. S. Semelhanças e diferenças na implementação de a gente em variedades do português. Tese (Doutorado em Letras Vernáculas) - Universidade Federal do Rio de Janeiro, Rio de Janeiro,235f, 2011

\section{Como referenciar este artigo}

CUNHA, Cátia Cilene Pereira Meireles; SILVA, Maricineia Pereira Meireles da. Descrição do quadro pronominal presente tanto nos principais compêndios gramaticais tradicionais quanto nas gramáticas de orientação linguística. Doxa: Rev. Bras. Psico. e Educ., Araraquara, v. 21, n. 1, p. 104-127, jan./jun. 2019. e-ISSN: 2594-8385. DOI: https://doi.org/10.30715/doxa.v21i1.12933

Submetido em: 01/11/2018

Revisões requeridas: 10/12/2018

Aprovado em: 10/01/2019

Publicado em: 01/02/2019 